\title{
HACIA UNA NUEVA POLITICA EXTERIOR DE CHILE
}

\section{Mario Matus Baeza}

\begin{abstract}
Ante los cambios producidos en el mundo, los países deben reade cuar las bases tradicionales de su quehacer externo. Según el autor, hoy los países en desarrollo y Chile en particular, tienen "la" oportunidad para salir de la marginalidad, para lo cual deben tomar decisiones en algunas áreas claves como la política exterior. En el nuevo escenario, es posible identificar ciertas megatendencias y microtendencias -no necesariamente coincidentes- que complican aún más la visión. Pero, al mismo tiempo, se distinguen tres ideas en torno a las cuales hay consenso: la democracia y la economía social de mercado, como medios, y el desarrollo, como objetivo de la sociedad. Chile, ha aprendido algunas lecciones y ha reaccionado, sin embargo esto no es suficiente y debe iniciar un proceso de redefinición de su participación en el mundo. Finalmente, se concluye que se requiere un nuevo Ministerio de Relaciones Exteriores y se mencionan algunas de las características que éste debería tener.
\end{abstract}

\section{Introducción: algunos supuestos.}

Los cambios producidos en el escenario mundial de los últimos años, obliga a todos los países a readecuar sus objetivos, medios y, eventualmente, principios acerca de lo que tradicionalmente han sido las bases axiológicas, programáticas e informadoras de su quehacer externo. Ello, particularmente referido a la sociedad Occidental, de la cual Chile forma parte, ${ }^{1}$ tanto en términos de valores sociales como individuales.

Si bien no ha llegado el "Fin de la historia y del último hombre", sí nos encontramos frente a un mundo nuevo y desconocido. El tablero ha sido dado vuelta y los referentes clásicos ya no se sostienen por sí mismos. Las piezas son distintas y "hay que reinventar el juego

\footnotetext{
${ }^{1}$ Por cultura occiđental entiendo la civilización y valores incoados y desarrollađos a partir de la Paideia Helénica, pasando por el Imperio Romano (juđaísmo y cristianismo) y la Europa subsecuente.

${ }^{2}$ Título del libro de Francis Fukujama.
} 
para este tablero diferente". Todo el esquema internacional ha de ser pensado y revisado.

El fin de la Guerra Fría tiene varias lecturas desde el punto de vista de los efectos históricos para los países en desarrollo. En un extremo estaria la noción de "la" oportunidad para estos países de ser más libres y dedicar esfuerzo y energía hacia a ellos mismos; con mayor prescindencia del entorno político-ideológico. En el otro y debido a la ausencia de distorsiones -positivas o negativas- en el sistema internacional, este nuevo entorno no haría más que consolidar la situación de marginalidad de los países pobres en el contexto mundial, sancionando una condena perpetua de miseria y subdesarrollo.

Este documento, parte de la base de que la realidad está más cerca de la primera versión. Más aún, propone que Chile sería uno de los países en desarrollo con posibilidades reales de salir del subdesarrollo. Para ello, sin embargo, es menester tomar hoy decisiones en algunas áreas claves (la política exterior entre ellas) para permitir tal destino venturoso.

En este sentido, a Chile le cabe perfectamente la siguiente metáfora: un único y largo tren, una sola línea y una solitaria estación terminal, con una capacidad para recibir pasajeros desconocida. Los que viajen en los primeros carros no sólo arribarán antes sino que aumentarán sus posibilidades de entrar a la estación. Los viajeros de los últimos vagones, quizá también lleguen, pero lo harán ulteriormente y con menores probabilidades de tener un espacio vital en la última parada. Chile se encuentra en una situación privilegiada para acceder a los primeros carros, pero para ello se requieren decisiones y acciones hoy; luego podrá ser tarde.

\section{Un cambio de rumbo en la historia.}

Los libros de crónica recordarán el día que cayó el Muro de Berlín, el 9 de noviembre de 1989, como un símbolo del fracaso del comunismo y por consiguiente del fin de la Guerra Fría. Las imágenes del satélite permitieron que la humanidad tomara conciencia; o, al menos, tuviera la percepción de que algo trascendente estaba ocurriendo a nivel mundial. Los más expertos previeron que sería el detonante del cambio más profundo en las relaciones internacionales desde el término de la Segunda Guerra Mundial. 
A partir de la década del cuarenta se estructuró un mundo bipolar con un conjunto de instituciones mediadoras de ambos bloques que dejaron de tener sentido y justificación con el colapso de los socialismos reales. Más que ontológico, fue un conflicto ideológi$\mathrm{co}$, excediendo lo meramente defensivo. ${ }^{3} \mathrm{De}$ allí que se crearan organizaciones político-bélicas ${ }^{4} \mathrm{y}$, al mismo tiempo, se estableciera un marco institucional para las cuestiones económicas, comerciales y financieras. 5

En aquel mundo bipolar, las naciones distintas de las superpotencias eran mucho menos libres para buscar un camino propio e independiente de desarrollo. Dependían de las potencias hegemónicas. Esto último era particularmente notorio en países pequeños. Siempre debieron optar por algún grado de alineamiento para minimizar los costos de la exclusión o aislamiento del sistema imperante; u, obtener beneficios del mismo, como ayuda económica, cooperación bélica, apoyo a su independencia, sistema de preferencias comerciales (aranceles " 0 " o muy bajos para productos de países en desarrollo), normas más laxas en materia de responsabilidad y rigurosidad en el manejo de las variables macroeconómicas, programas de cooperación técnica, etc.

\footnotetext{
${ }^{3}$ Se trataba de un enfrentamiento entre dos concepciones acerca de la naturaleza humana y de una contienda axiológica; la preeminencia entre dos valores: libertad e igualdad. Estos se caracterizan por ser inversamente proporcionales en su aplicación. Privilegiar la libertad resulta en mayor desigualdad; si se prefiere la igualdad, la conculcación de grados de la libertad será su consecuencia.

${ }^{4}$ En el mundo capitalista destacaron la Organización del Atlántico Norte (OTAN); el Tratado Interamericano đe Asistencia Recíproca (TAR); Australia, Nueva Zelandia y Estados Unidos (ANZUS); y, en el socialista, el Pacto de Varsovia.

${ }^{5} \mathrm{El}$ sector del mundo que no confiaba en el mercado, optó por un sistema de trueques y compensaciones para el intercambio comercial entre los países del bloque. Ese fue el COMECON, que reunía a los países đe Europa del Este y la Unión Soviética. Occidente prefirió las fuerzas del mercado y tres pilares: el Banco de Reconstrucción y Fomento (BIRF), el Fondo Monetario Internacional (FMI) y la Organización Internacional del Comercio (OIC).

La orc aseguraría el libre mercado, satvaguardando un mínimo de normas de seguridad social y de protección al trabajador, pues, aquél que había dado su sangre por la democracia y el capitalismo, bien merecía una normativa que reconociera tal dignidad. Como la organización tardaría en formalizarse, sus miembros-Chile entre ellos-acordaron aplicar provisionalmente la sección đestinada a remover los aranceles aduaneros. Ese fue el Acuerdo General sobre Aranceles y Comercio (General Agreement on Tariff and Trade: GATT). Finalmente el Congreso de los Estados Unidos rechaz6 el proyecto, quedando como único sobreviviente de la OIC, este hibrido llamado GATT; cuyos principios y reglas hoy gobiernan la mayor parte del comercio mundial de mercancías.
} 
En no pocos casos, ello fue el origen de contradicciones y de situaciones hibridas: economías capitalistas en el discurso pero tremendamente protegidas respecto de la competencia externa; países explícitamente socialistas formando parte de la institucionalidad occidental; ${ }^{6}$ Estados que decían aceptar el comercio internacional como medio del desarrollo que se auto excluían del GATT; democracias meramente formales; regímenes militares disfrazados de legitimidad democrática; regímenes comunistas en los que la dictadura del proletariado no era más que un eufemismo para denotar gobiernos autoritarios y personalistas, siendo la corrupción un común denominador bastante generalizado; el propio Movimiento No Alineado albergaba todo tipo de países, algunos claramente alineados con alguno de los extremos alternativos.

Con el desmembramiento del imperio soviético, los parámetros y las limitantes de la Guerra Fría dejaron de existir y -con ello- los puntos de referencia de los actores del concierto internacional para establecer estrategias, finalidades y metas en el área externa. La necesidad de repensar la política exterior, entonces, surge con fuerza tanto para los países desarrollados, como en vías de desarrollo y los menos adelantados. ${ }^{7}$

En términos de resultado, sin embargo, lo anterior no ha sido lo suficientemente motivador como para promover los necesarios debates nacionales tendientes a derivar propuestas operativas de cambio. Más aún, hasta la fecha no se aprecian definiciones claras de los principales actores de la escena mundial. Por el contrario, se percibe cierta incoherencia, inacción o falta de oportunidad en el actuar. ${ }^{8}$ Sólo algunos países industrializados pequeños y en vías de

\footnotetext{
${ }^{6}$ Yugoslavia fue el más claro ejemplo: parte contratante de GATT, en UNCTAD funcionaba en el G.77 en lugar del Grupo D (el socialista), miembro asociado de la OCDE, etc,

${ }^{7}$ A dichas circunstancias de carácter estructural habría que agregar elementos netamente coyunturales que ayudan a obnubilar el panorama: elecciones disputadas o referenda muy importantes para ser demasiado equiiibrados en países de primer orden (Estados Unidos y Francia), duda razonable acerca de la viabilidad de Maastricht, procesos de contracción o desaceleración económica en América del Norte, Europa y Japón, crisis o guerra civil en la ex-Yugoslavia, inestabilidad política en las repúblicas que conformaron la Unión Soviética, recurrente pobreza y hambruna en Africa, etc.

${ }^{8}$ Estados Unidos no ha sabiđo enfrentar debjdamente los cambios en la ex-Unión Soviética o la crisis Yugosiava. Alemania ha impulsado ciertas líneas dé acción en đichos escenarios, aunque también ha carecido de la fuerza (sobre todo económica) por el costo de su propia reunificación. El rechazo al Tratađo de Maastricht en Dinamarca, el alto porcentaje de opiniones negativas en Francia y la crisis del Sistema Monetario Europeo, tampoco son señales claras acerca de lo que se quiere como destino, y hasta dónde se desea llegar.
} 
desarrollo comienzan a dar muestras de alguna lucidez en la obscuridad reinante: metas precisas y definidas para el quehacer externo. ${ }^{9}$

\section{El futuro.}

Aun cuando es difícil predecir el futuro mediato, Occidente ya deja entrever algunos de los elementos que conformarán la sociedad del mañana. En efecto, ya se vislumbran algunos lineamientos generales y aplicables globalmente (megatendencias). También se aprecian, no obstante, hechos o actitudes específicas y puntuales (microtendencias), que no necesariamente coinciden con las propensiones generales, complicando aún más la visión del mundo postmóderno.

\section{Megatendencias.}

- Universalización del respeto a los derechos humanos. Este proceso está conduciendo a la idea de calificar por el resultado la acción de los gobiernos en este ámbito. Ya no bastan buenas intenciones ni los "apoyos políticos". El respeto a tales derechos se está confirmando como un parámetro objetivo para medir la calidad y eventualmente legitimidad de un determinado gobierno. Por esta vía el individuo está llegando a ser un actor importante e independiente en la escena internacional, hasta hace poco del dominio exclusivo de los Estados. ${ }^{10}$

- La democracia como sistema básico de gobierno. Este consenso y el de los derechos humanos podrían llegar a modificar uno de

\footnotetext{
${ }^{9}$ Algunos ejemplos de países y algunas de sus políticas: Canadá, si bien tiene un Acuerdo de Libre Comercio con Estados Unidos, impulsa los vínculos con el Pacífico; tiene claras políticas de inmigración; yes un gran proveedor de ayuda para el desarrollo. Nueva Zelandia y Australia: sin desconocer ni rechazar sus vínculos con el Reino Unido y membrecía en la OCDE, han aceptado su calidad de países "asiáticos", promueven el acercamiento comercial con América Latina y se distinguen por un discurso liberal en lo económico. México: participación en la $O C D E$, NAFTA, miembro del BERF y acuerdos de libre comercio con pajses de América latina. Argentina: claro alineamiento con Estados Unidos, renuncia expresa a los No Alineados y un decidido esfuerzo por cambiar su imagen internacional. Corea del Sur: eventual ingreso a la OCDE junto a México, evidente énfasis en las relaciones económico comerciales, un nivel de "cuasi desarrollado" y sin embargo pretende usar las ventajas de los países en desarrollo.

${ }^{10}$ En la Convención Europea de Derechos Humanos y en la Convención Americana de Derechos Humanos (Pacto de San Jose), los individuos o grupos pueden acceder directamente a su jurisđicción, sin necesidad de mediación del Estado nacional a cuyo imperio se encuentra sujeto.
} 
los pilares del sistema jurídico internacional del presente como es el "principio de no intervención en asuntos internos". Hoy se habla del "deber de injerencia" cuando la democracia es el bien protegido.

- Distanciamiento entre el poder económico y el político-bélico. Es tal vez el elemento más claro en todo este panorama. En el pasado ambas capacidades han ido de la mano e inextricablemente unidas. Hoy la mayor empresa de guerra de la historia de poco o nada le sirve a Estados Unidos para mantener o mejorar el nivel de vida de sus habitantes. A la inversa, Japón -contra su voluntad-ha debido incrementar su esfuerzo en defensa y seguridad. ${ }^{11}$ Esta realidad tiene dos características, a saber: un cambio de un mundo bipolar por uno multipolar, tanto en términos económicos como político-defensivos; y, mayor énfasis o preeminencia de lo económico comercial por sobre consideraciones más clásicamente políticas, culturales o de otro tipo.

- La economía de mercado aparece como el único referente, que funciona adecuadamente para los valores imperantes. Es dable esperar, entonces, mutaciones importantes en el sistema multilateral político o económico; varias de las cuales ya se están produciendo o existen propuestas sobre el particular. De allí que se hable de crisis del multilateralismo, especialmente el vinculado al mundo económico. ${ }^{12}$

- Cambio estructural en el comercio internacional. Como consecuencia de los procesos de apertura comercial, en la segunda mitad de los ochenta, el volumen del comercio mundial creció a tasas superiores al 6\%. En 1990 fue de 5,4\% y en 1991 una cifra similar. ${ }^{13} \mathrm{El}$ comercio muestra un gran dinamismo en aquellos

${ }^{11}$ Los US\$10.000 millones aportados por Japón para la Guerra del Golfo no disminuyó la presión para que éste asuma el lugar que le corresponde en el escenario político internacional. Algo equivalente le sucede a Alemania, con el ingrediente de mayor cautela por parte de sus pares europeos.

${ }^{12}$ La Organización de Naciones Unidas (ONU) ya modificó el Ecosoc, y el Secretario General -Boutros Ghali- se haya en un claro proceso modernizador, proposiciones para un Consejo de Seguridad más coherente con el poderío relativo de ciertos países; Organización de Estados Americanos (OEA), donde existen propuestas de cambios; el GATT y la nueva OIC; UNCTAD y su proceso de redefinición ante su incapacidad operativa: el devenir de la Ronda Uruguay, la Organización Mundial de la Propiedad Intelectual (OMPI) perdería parte de su actual sentido con la Propieđad Intelectual dentro del nuevo GATT; ALADI y su incompetencia frente a los procesos de acuerdos regionales en desarrollo; etc.

${ }^{13}$ Aún no se disponen de las guarismos definitivos de 1991. Para 1992 se esperan cantidades algo menores. 
sectores que incorporan un alto valor agregado. Por su parte, la .producción mundial, fue del orden del $2 \%$ en 1990 , algo menor en 1991 y 1992 . Consecuentemente, si bien en lo coyuntural se debe esperar una desaceleración del comercio, se ha estado produciendo un cambio de fondo en este ámbito. La dirección del comercio también ha sufrido una mutación de importancia, al desplazarse el tradicional centro de gravedad del comercio del Atlántico Norte (eje Estados Unidos-Europa) hacia el Pacífico.

- Los flujos financieros internacionales se ven marcados por el persistente déficit norteamericano, país hacia el cual siguen fluyendo las grandes corrientes de financiamiento internacional, con las subsecuentes distorsiones. Por otra parte, las fuentes de ahorro mundial también se han desplazado, emergiendo Japón y Taiwán con gran superávit comercial y como importantes acreedores planetarios. Otro clásico motor comercial, Alemania, se ha visto afectada por su proceso de reunificación aumentando el gasto interno, al grado que el Banco Central bajó las tasas de interés ${ }^{14}$ y se habla de incrementar los impuestos para 1994.

- Además de la evidente velocidad del progreso tecnológico, ${ }^{15} \mathrm{su}$ incorporación en el desarrollo de las ventajas comparativas ha demostrado ser un instrumento de primer orden en el proceso de inserción de un país en el comercio internacional. Por su intermedio se han "cultivado nichos" que permiten el desarrollo de ciertos sectores que han cumplido la función de motores de la economía doméstica. Es probable que este modelo continúe utilizándose.

- Existe una clara tendencia hacia el regionalismo, varios de los cuales pueden devenir en efectivos bloques comerciales la $\mathrm{Co}$ munidad Económica Europea (CEE), su acuerdo con los países de la Asociación Europea de Libre Comercio ${ }^{16}$ y la llamada Area Económica Europea (AEE), más los países de Europa del Este; Estados Unidos y su Iniciativa para las Américas; Japón y la

\footnotetext{
${ }^{14}$ Para expandir la masa monetaria y reactivar la economía. Ello fue una señal de inestabilidad y produjo una desconfianza que coadyuvó a la crisis del Sistema Monetario Europeo en septiembre pasado: la libra y la lira salieron de él y la peseta se đevaluó en un $5 \%$.

${ }^{15}$ Se ha escrito bastante literatura acerca del cambio de la tecnología, su impacto en la vida diaria y sus diferentes grados de velocidad dependiendo del área de que se trate. Se conjetura, por ejemplo, que si la industria del automóvil hubiese avanzado al mismo ritmo que la computación, hoy un Rolls Royce costaría US $\$ 1$ y sería capaz đe andar 1 millón de kilómetros con 1 litro de bencina.

${ }^{16}$ EFTA O AELE, en siglas inglesas o francesas, respectivamente.
} 
ASEAN; el proyecto APEC; $y$, el Norte de Africa. De consolidarse el proceso y no obstante que su origen es meramente comercial, fácil es que devengan en acuerdos más amplios, con mayor contenido político ${ }^{17}$ y 18

- Se mantendrán o incrementarán los niveles de pobreza, tanto en términos cualitativos como cuantitativos. El $75 \%$ de los seres humanos que habitan esta tierra viven en un estado de carencia. El 20\% de éstos califican de indigentes sin esperanzas, es decir, personas para las cuales la noción de dignidad no es más que una quimera; que no hacen más que degradarse física y moralmente para intentar satisfacer las necesidades elementales de la existencia. ${ }^{19}$ Unicamente en Somalia mueren entre 2.000 y 5.000 personas diariamente como resultado del hambre y la guerra. ${ }^{20}$ Todo elló frente a una minoría que usa, goza, ostenta de la riqueza y el poder que ella genera para su propia autoperpetuación.

- Se percibe una creciente tendencia a los desequilibrios y desigualdades internas en los procesos de desarrollo de los países. Hoy en la ciudad de Nueva York, hay individuos normales que viven con ingresos per cápita que pueden fluctuar entre los 100 o 300 mil dólares al año, con expectativas de vida de cerca de 80 años y sin saber qué hacer con el tiempo libre. Literalmente, en la misma ciudad, a pocas cuadras de distancia, otros estadounidenses viven en condiciones de higiene, salubridad, nivel y expectativas de vida no envidiables por hambrientos de Zaire o Somalia. Brasil, la octava economía del mundo y con grandes y ricos polos de

\footnotetext{
${ }^{17}$ Una posible clasificación de tales entidades pođría ser la siguiente: Los semiconsolidados, con estructura jurídica y en función total o parcial y con un alto grado de integración. Aquí ubicaría la Europa de Maastricht y el Acuerdo de Libre Comercio Estados Unidos-Canadá y, eventualmente, el Acuerdo de Libre Comercio de Norteamérica, entre Estados Unidos, Canadá y México (NAFTA). Los proyectos en formación que no se encuentran realmente consolidados. Es el caso de Estados Unidos y la Iniciativa para las Américas; la AFTA, el MERcosur; los países đel Norte de Africa, del Magreb; quizás, Europa del Este; y, acaso en un futuro no lejano, un eje chino-japonés. Los económicos reales, que no tienen una estructura juridica, pero que tienen características de bloque en ciertas oportunidades. Este sería el caso de Japón y sus socios inmediatos como Corea y otros del sector; y, a veces, la ASEAN. Los marginales, en términos de importancia mundial tienen poca incidencia, como el pacto ANDNO; Mercado Común del Caribe; o, la red de acuerdos comerciales que firma Chile, etc.

${ }^{18}$ Entendiendo éstos como un grupo đe países que primero negocia entre ellos para luego tener una posición externa frente a terceros común y única.

${ }^{19}$ En otros términos, de los 5.200 millones que habitan el pianeta, aproximadamente 4.000 millones viven en la pobreza; 1.000 millones sufren la indigencia y más de 400 millones pasan hambre.

${ }^{20}$ Informe anual de "Bread for the World", presentado por David Beckmann el 15 de octubre de 1992.
} 
M. Matus B. / Hacia una nueva política exterior ...

desarrollo como São Paulo, convive con una de las zonas más pobres del planeta: el Noreste brasileño. Se pueden esperar, entonces, importantes tensiones al interior de los Estados por esta causa.

- La situación descrita está generando apremios en los flujos migratorios internacionales y aumentando el número de refugiados. ${ }^{21}$ Ello, a su vez, incrementa 'el riesgo de proposiciones populistas o reacciones bélicas como respuesta a la inquietante pauperización. Es fácil prever que esta materia también será fuente importante de tensiones futuras.

- Las rígidas categorías económicas entre países desarrollados, en vías de desarrollo y menos adelantados; lo mismo que las nociones de primer (desarrollados), segundo (socialistas) y tercer mundo (subdesarrollados), que tuvieron su origen durante la Guerra Fría hoy son meros bosquejos de una realidad más rica, variada y fluida.

- Si de categorías se trata, se está incoando una nueva pero real división entre los miembros de la comunidad internacional: proteccionistas frente a los liberales (independientemente de su grado de desarrollo). El alto grado de interdependencia entre los países, evitará guerras comerciales al estilo de los años treinta, pero es probable que se constituya en una de las fuentes de tensiones futuras. En efecto, los países industrializados continúan pregonando el libre comercio y el sano manejo de la economía, al tiempo que mantienen distorsionadores déficit fiscales, escalonamiento arancelario, alta protección en áreas como la agricultura, el acero, los textiles, sectores automotrices, ciertas tecnologías de punta, algunos sectores de servicios, ${ }^{22}$ etc. Como curioso contrapunto, muchos países pobres efectúan ajustes estructurales, con grandes costos sociales y comienzan a presionar por la apertura de mercados y oportunidades comerciales, con reglas internacionales claras y predecibles.

\footnotetext{
${ }^{21}$ Desde 1984 el número de refugiados se ha duplicado a 18 millones en todo el mundo, encontrándose otros 20 milliones desplazados dentro de sus propios países. Informe de "Bread for the World", citado.

${ }^{22}$ El ejemplo clásico ha sido la Ronda Uruguay, donde el tema de los scrvicios fue impuesto por Estados Uniđos y, sin embargo, a međida que avanzaba la negociación comenzó a establecer excepciones o exclusiones que, en definitiva, dejarian a un restringido sector de servicios sujeto a las normas GATT. De hecho, hoy es la CEE la que condiciona una eventual reestructuración de la política agrícola común (PAC) a una mayor apertura de Estados Unidos en los servicios.
} 
- La idea de un medio ambiente libre de una excesiva contaminación conllevará cambios profundos en el actuar internaciọnal. De hecho, ya constituye un notorio mecanismo de presión que está creando herramientas, modelos y conceptos a nivel internacional para asegurar buena calidad de vida a las generaciones futuras. Ejemplo: la noción de desarrollo sustentable.

- El avance de los sistemas de teledetección y percepción remota está desdibujando la noción de las fronteras nacionales. ${ }^{23} \mathrm{En}$ efecto, la capacidad de observar el globo terráqueo y utilizar dicha información para fines operativos, es una realidad. Hoy, gobiernos y empresas privadas auscultan cientos de veces por día la Tierra por motivos tan diversos que van desde la detección de recursos pesqueros, agrícolas, forestales y mineros, hasta la regulación del tránsito en la ciudad de San Francisco, pasando por la predicción climatológica, la protección frente al enemigo, la transmisión de ondas televisivas, telefónicas, de radio, etc.

- Es evidente la erosión del principio de soberanía y la aceptación de que el-capital propiamente tal no tiene nacionalidad. ¿Qué sentido tiene hoy, la idea por la que hace veinte años se rasgaban vestiduras y se iniciaban sangrientas guerras? ${ }^{24}$ Para muchos, hoy tendría más valor el bienestar que produce aquel capital que el concepto de soberanía "per se".

- El avance de las comunicaciones y del transporte están cambiando muchas instituciones y disciplinas, la diplomacia entre ellas. En efecto, la globalización del quehacer humano implicará que lo que ocurra en un lugar del mundo no podrá ser irrelevante para el resto. En el siglo XXI la idea de Aldea Mundial bien pudiera llegar a ser realidad. ${ }^{25}$ La globalización también implica la generación de "problemas" de escala mundial: medio ambiente, el

${ }^{23}$ Cuando viajó al cosmos el primer transbordador espacial se requería determinar si las placas cerámicas del escudo de la nave habían soportado el despegue. A tal efecto se "miro" desde la tierra y se comprobó que faltaban piezas de 15 a 30 centímetros que, afortunadamente, no afectaŕan el reingreso. Pero, isi es posible detectar objetos de esa magnitud desde la Tierra a la órbita terrestre, por qué no a la inversa?

${ }^{24}$ Cabe recordar las proposiciones dentro de UNCTAD respecto del derecho permanente de los países sobre sus recursos naturales.

${ }^{25}$ Baste para ello recordar el papel de los medios de comunicación en los últimos acontecimientos que han conmovido al mundo: guerra del Golfo, la caída de Ceaucescu, la guerra civil yugoslava, el intento de golpe en la ex-Unión Soviética, hambruna en Somalia, etc. Es evidente que, en ese contexto, la clásica labor de información de la diplomacia tradicional pierde bastante sentido ante la existencia de estos; adquiriendo mayor relevancia las evaluaciones de impacto y proyecciones de tales hechos. 
crecimiento demográfico y el incremento de las migraciones, pandemias, narcotráfico, terrorismo, corrupción, etc.; todos los cuales también requieren estrategias globales.

- La sociedad occidental sufre una mutación en los ciertos valores, que terminan afectando el quehacer exterior de los Estados. Para muchos pareciera ser hoy más importante vivir más y mejor que morir por la idea etérea de una bandera, una isla o un líder; la concepción de familia cambia rápidamente, la "soledad del ser humano" pasa a ser un lugar común en conversaciones triviales y una preocupación de la política. En fin, para importantes sectores hoy tienen mayor valor ético las fuentes de trabajo que las fronteras, el "tener" que el "ser", la opulencia que la austeridad, el individuo que la sociedad, la calidad de la vida que la vida misma. $^{26}$

\section{Microtendencias.}

- Nuevos idearios de regionalistas y nacionalismos exacerbados. ${ }^{27}$

- Fanatismos religiosos y procesos de búsqueda de coherencias axiológicas. El avance del Islam, especialmente el fundamentalismo, en el Medio Oriente y el Norte de Africa; el aumento en el número y variedad de sectas para los más distintos objetivos y fines; la aparente pérdida de terreno de la Iglesia Católica Apostólica Romana frente a las Iglesias Protestantes en países clásicamente católicos, etc.

- Modas xenofóbicas y el renacer de sentimientos antiextranjeros simbolizados por los "Skinhead", entre cuyas complejas causas -además de psicológicas- se hallan los problemas económicos y los procesos de migraciones antes citadas.

- Los enfrentamientos culturales también se vislumbran como el típico foco de violencia futura. Aparentemente, la embestida será entre culturas que utilizan las mismas herramientas, aunque con objetivos y teleologías diferentes.

${ }^{26}$ Algunos đirán que es relativismo moral; otros, simplemente, variedad axiológica. El hecho es que hay una mutación en los valores de las grandes mayorias, los que difieren bastante de los prevalecientes a comienzos del siglo $\mathrm{XX}$.

${ }^{27}$ La ex-Yugoslavia, la ex-Checoslovaquia, los países desmembrados del imperio soviético, movimientos indigenistas, etc. 


\section{Ideas para un nuevo mundo: algunas nociones éticas.}

En la versión optimista del futuro, el nuevo orden mundial otorga mayor libertad y un enorme espacio para la búsqueda de valores más trascendentes que la mera supervivencia de los Estados y las nacionalidades. Hoy el humanismo 28 tendría una oportunidad real.

En efecto, para aquellos que postulamos al hombre como centro del quehacer político-económico-social, un mundo sin enfrentamientos ideológicos permite el desarrollo y profundización de principios éticos considerados deseables y positivos por la civilización judeo-cristiana-occidental: la libertad, la igualdad, la solidaridad, la cooperación, la equidad, respeto por el individuo y las ideas ajenas, la tolerancia, la seguridad y la aceptación de la necesidád de limitar el poder temporal: 29 .

Sin perjuicio de lo anterior y no obstante la complejidad del mundo político posterior a la Guerra Fría, se pueden distinguir ciertas regularidades profundas y operativas para el quehacer humano respecto de las cuales habría genérico consenso, en tres ideasfuerza: la democracia, la economía social de mercado ${ }^{30}$ y el desarrollo como objetivo de la sociedad. ${ }^{31}$ Más aún, algunos dicen que hoy la democracia exige desarrollo y el desarrollo exige democracia.

\section{Chile frente al nuevo mundo.}

Aun cuando no se ha producido formal y explícitamente un cambio en la política exterior de nuestro país, en el hecho Chile ha aprendido ciertas lecciones y ha actuado en consecuencia. En efecto, a partir de

\footnotetext{
${ }^{28} \mathrm{De}$ hecho varios de los elementos mencionados en los literales precedentes se ubican inđiscutiblemente en la categoría de preocupación "por y para" el ser humano.

${ }^{29}$ Parte importante de estos principios tienen sus raíces en el mundo helénico. Ver Paideia: los ideales de la cultura griega de Werner Jaeger, La vida coridiana en Grecia del siglo de Pericles de Robert Flaceliere; El origen de La Tragedia de Nietzsche; $y$, La esencia de la Tragedia Griega de A. J. Festugiere.

${ }^{30}$ En el entendido de que la ausencia de conflicto global permitirá destinar mayores recursos humanos y financieros a la asistencia de los más necesitados, bajo el supuesto es que ello coadyuvaría a encauzar tensiones, morigerar el diálogo entre los sectores del proceso productivo, allanax el camino para la búsqueda de soluciones de consenso y obligar -de paso- a esforzarse en comprender la racionalidad del otro.

${ }^{31}$ Entendido como el proceso a través del cual los pueblos obtienen más y mejores niveles de vida en un contexto de relativa justicia sacial, con buena distribución del ingreso y en el convencimiento de que este último sentido ético es necesario para la mantención del propio sistema.
} 
marzo de 1990, y como resultado del proceso de reinserción de nuestro país en el sistema internacional, se pueden apreciar ciertas regularidades en el accionar externo de Chile y que pueden resumirse en las siguientes: se promueven los derechos humanos, independientemente del sistema político de que se trate; se manifiesta abiertamente, a modo de aspiración, la generalización de la democracia como sistema de gobierno; al reconocer y aceptar el poder y capacidad real de Chile en el contexto mundial, se privilegia el pragmatismo operacional antes que el clásico protagonismo formal o protocolar; ${ }^{32}$ por ser país pequeño mantenemos una clara vocación en este sentido, lo que no significa descartar el bilateralismo o plurilateralismo en tanto cuanto no contradice tales principios multilaterales (los Acuerdos de Libre Comercio acordados y por negociar deben ser compatibles con las normas GATT); valoramos la flexibilización de los esquemas de concertación internacional y se favorecen nuevas e innovadoras formas de asociación como son los grupos de interés: Cairns, Grupo de Río, de la Paix, Grupo Internacional de Estudios del Cobre, entre otros.

Si bien tales reacciones han sido adecuadas no son suficientes para el futuro. Se requerirá una acción internacional más definida y teniendo como norte una nueva política exterior. De allí que los principios tradicionales de la política exterior chilena (no intervención en asuntos internos de otros Estados, intangibilidad de los tratados, rechazo al uso o la amenaza del uso de la fuerza, respeto al Derecho Internacional, integridad territorial, solución pacífica de las controversias, apoyo al sistema multilateral, promoción de la paz mundial y regional, etc.) siguen vigentes para el quehacer exterior, pero carecen de la idoneidad operativa que las necesidades del futuro imponen. Es decir, son condición necesaria pero no suficiente.

En este escenario de búsqueda Chile debería iniciar seria, coherente y por la vía del consenso, un proceso de redefinición de nuestra participación en el mundo. Ello no sólo pasa por la adaptación de los principios clásicos señalados, sino por responder preguntas como ¿cuál es el Chile que deseamos en diez años más?; y, ¿qué puede o debe hacer el sector externo para ello?

En realidad, basta un análisis lineal, con todos los riesgos que ello importa, ${ }^{33}$ para concluir que en los inicios del próximo siglo Chile

\footnotetext{
${ }^{32}$ Por ejemplo, más importa ubicar chilenos en puestos de alto nivel de influencia en el sistema internacional, antes que un número importante de los mismos.

${ }^{33}$ Se supone que la bonanza económica se mantendrá y que las tasas de crecimiento serán iguales o superiores al $6 \%$ anual.
} 
será un país distinto, ya que habrá duplicado el ingreso per cápita, ${ }^{34}$ lo que cambiará los hábitos de consumo y por ende la estructura del comercio internacional. El mayor bienestar relativo afectará las necesidades del individuo medio y de la sociedad en su conjunto, modificando sus patrones de gasto, incluso sus valores, preocupaciones e intereses.

Los montos acumulados por las Administradoras de Fondos de Pensiones estarán cerca de su punto de equilibrio lo que dará cifras de ahorro interno equivalentes al PGB. ${ }^{35}$ Ello dará mayor estabilidad al sistema y obligaría a aumentar inversión chilena en el extranjero; pues la economía nacional difícilmente podría absorber tales cantidades de recursos.

Las exportaciones chilenas estarán mucho más diversificadas y con énfasis en productos de mayor valor agregado, diferenciándose de la actual estructura, centrada en la exportación de productos básicos. ${ }^{36}$ Ello supone -entre otras cosas- cambios en variables internas como el sistema educativo nacional, la infraestructura vial, de ferrocarriles, de puertos, de comunicaciones, la mentalidad del pequeño y mediano empresario, etc. En lo externo también variará la concepción de cómo se inserta Chile en el mundo y la forma en que los exportadores utilizan dicha realidad para sus intereses.

La economía en su conjunto habrá incrementado su proceso de internacionalización, lo que hará a nuestro país más dependiente del sistema de comercio internacional ${ }^{37}$ y lo obligará a buscar con más ahinco un sistema multilateral estable, transparente, predecible, con reglas generales claras y objetivas.

\footnotetext{
${ }^{34}$ Hoy algo superior a los US\$ 3.000 , aunque ajustados por el poder de compra se elevaba ya en 1991 por sobre los US\$ 7.000.-, Banco Mundial, citado por Claro y Asociados en El Mercurio del 5 de octubre de 1993.

35 "Boletín Estadístico", №110, abril 1992, Superintendencia de Administradoras de Fondos de Pensiones.

Es necesario advertir, no obstante, que en reciente trabajo de la Organización Internacional del Trabajo (Orr), publicado en el Intemational Labour Review, vol. 111, Ne 2, Gillion y Bonilla, analizan el sistema de las AFP chilenas, realizando proyecciones menos optimistas respecto de su futuro.

Cabe anotar que The Economist (3 de octubre de 1992) comenta dicho artículo, abonando en cierto sentido el mismo, lo que vendría a contradecir anteriores opiniones del mismo semanario respecto del sistema.

${ }^{36}$ Existe una relación directamente proporcional entre el mayor valor agregado y el mayor arancel aduanero aplicable al producto. Es el llamado escalonamiento arancelario, de cual Chile se verá afectado en la segunda etapa o fase del programa de exportaciones.

${ }^{37}$ Hoy cerca entre el $30 \%$ y $70 \%$ (depende del año) del PGB del país está vinculađo al comercio exterior (importaciones más exportaciones). Es uno de los porcentajes más altos del mundo.
} 
Las empresas chilenas habrán aumentado considerablemente sus inversiones en el exterior y sus productos entrarán en competencia con equivalentes de países desarrollados, lo que las enfrentará a nuevos y más sofisticados desafíos. ${ }^{38}$

Si bien Chile distará aún de ser un país desarrollado en la concepción actual, será lo suficientemente distinto como para imponerle obligaciones internacionales de otro carácter. Para ello se requiere llevar a cabo gestiones hoy, para darle una oportunidad a ese futuro; de lo contrario habremos dejado pasar el tren.

\section{La nueva política exterior.}

La función principal de la política exterior es potenciar la capacidad natural de Estado. Luego, si ésta es bien definida y posee un eficiente órgano ejecutor, el país debería lograr un poder de influencia mayor que el que tendría de no mediar dicha acción concertada. La inacción perjudica las posibilidades de las generaciones futuras; pero, el llevarlo a cabo en forma torpe, pone en riesgo la credibilidad, la seriedad y el respeto a la palabra empeñada. ${ }^{39}$

Dentro de ese contexto, Chile podría racionalizar una política exterior sobre las siguientes bases:

\section{Un objetivo.}

Se debería establecer una única, pero motivadora idea como fin áltimo del país en lo externo. Si en la cima de la pirámide se cuenta con un concepto relativamente preciso, mucho se simplifica el análisis de los cursos de acción posibles. Dicho fin, empero, debería tener ser un equilibrio entre dos rasgos contradictorios: tanto desde el punto de vista técnico como de sentido común, debe ser un concepto lo suficientemente amplio o difuso, como para hacerlo virtualmente inalcanzable; $y$, ha de ser una noción lo suficientemente acotada

\footnotetext{
${ }^{38} \mathrm{Hoy}$, por exportar productos básicos, nuestros principales competidores son generalmente los propios páses en desarrollo. Ello significará mejorías en los niveles de competitividad, problemas para accedera los mercados extranjeros, mayores y más sutiles barreras comerciales, formas encubiertas de competencia desleal (acusaciones de dumping y subsidios), prácticas comerciales restrictivas, etc.

${ }^{39}$ Chile es el país en desarrollo que más disputas ha tenido con la Comunidad Económica Europea en el GATT. Nuestra imagen, entonces, es la de un país dispuesto a usar el sistema de solución de diferencias hasta sus últimas consecuencias.
} 
como para delinear cauces de los cuales puedan derivarse sendas operativas.

Para Chile, el punto focal de una nueva política exterior debería ser la noción de "desarrollo". Ello facilitaría, por ejemplo, las decisiones respecto del número y calidad de Embajadas, ${ }^{40}$ la participación en los diferentes foros internacionales, la asociación con determinados grupos de países, la formación de grupos de interés, etc. En fin, todo pasa a ser función de la utilidad de tales acciones para el objetivo definido.

Aunque en los dichos tal objetivo sigue siendo el mismo que hace treinta años, tanto las motivaciones como los argumentos han cambiado. ${ }^{41}$ En el pasado la idea de desarrollo tenía mucho de dádiva y poco de esfuerzo; hoy, en cambio, se esgrime el refrán de la sabiduría china, que es preferible "enseñar a pescar antes que regalar el pescado".

El Desarrollo, entonces, supone la búsqueda de factores extraeconómicos como puede ser la equitativa distribución del ingreso, la eliminación de la pobreza, la protección del débil, calidad de vida, etc. De ello se deriva que también debería existir cierto acuerdo en el sentido de que la "mano invisible" de Adam Smith no sería suficiente para la consecución de tal objetivo. ${ }^{42}$

En otros términos, para el desarrollo futuro se requieren acciones positivas del Estado nacional, con el apoyo del sistema internacional. $^{43}$

\footnotetext{
${ }^{40}$ Intuitivamente, tener Embajada residente en Estados Unidos parece útil para el desarrollo; no lo es tanto, en casos como Gabón, Burundi, Yemen o Uzbekistan.

${ }^{41}$ En la década del sesenta, Raymond Barre (el mismo de la centro derecha de hoy en Francia) en su libro El Subdesarrollo; escribió que el mundo se đividía en dos grupos de personas: "Jos que no podían dormir en la noche porque tenían hambre; $y$, los que tampoco podían dormir porque tenían miedo que los del primer grupo se sublevaran". Esa situación obligaba a la cooperación y la concertación económica internacional.

${ }^{42}$ Hoy se ha elaborado del concepto económico de las "externalidađes positivas" y "externalidades negativas" para justificar acciones sobre el libre juego de la oferta y la demanda, a fin de minimizar distorsiones. Es decir, la intervención estatal sería necesaria cuando la realidad no permite el eficaz funcionamiento del mercado (ver Tullock, Gordon, Private Wants, Publics Means: An Economic Analysis of the Desirable Scope of Govemment, (Nueva York: Basic Book, 1970), y Rhoads, Steven, Visión Económica del Mundo: gobierno, mercados y politica pública, (México: Trillas, 1990).

${ }^{43}$ Se cuenta en Ginebra que, en una oportuniơad, un periođista occidental preguntó a Raúl Prebisch, a la sazón Secretario General de UNCTAD, ipor qué la Secretaría del organismo siempre estaba a favor del grupo de países en đesarrollo, que por qué no era más neutral?. Prebisch habría respondido: "La Secretaría de UNCTAD es tan neutral frente al Tercer Mundo y la pobreza como lo puede ser el Director de ĺa Organización.Mundial de la Salud frente a la Malaria".
} 


\section{Principios.}

Para sostener el proceso de desarrollo del país es indispensable modernizar su accionar externo. Además de los tradicionales principios de la política exterior chilena, el "aggiomamiento" debiera pasar por: aceptar la indivisibilidad del accionar político y económico en la esfera internacional. Deben constituir una unidad en materia de decisiones y organización. En este nuevo mundo el componente mercantil tendrá mayor preponderancia, pero no será el único, ni excluyente; la mantención y expansión de los mercados de exportación de los productos chilenos, la promoción de la inversión extranjera en el país y la protección a la inversión chilena en el exterior; mayor diálogo y cooperación entre el sector público y el privado en la implementación de la política exterior chilena. La decisión final, sin embargo, debe ser tomada por la autoridad política que corresponda ${ }^{44}$ Mientras el Estado sea el principal actor internacional, su participación será necesaria en dos instancias de negociación: ex-ante, donde el Estado chileno conducirá las negociaciones multilaterales y bilaterales económicas y políticas, para lo cual requiere de personal especializado; $y$, ex-post, cuando los canales judiciales, arbitrales o comerciales privados no sean conducentes a la solución de los problemas, las empresas deberán acudir al "conducto regular"-el Estado- para solucionar sus querellas. Esa es una realidad que ya la comienzan a vivir varios sectores nacionales.

\footnotetext{
${ }^{44} \mathrm{Si}$ bien el motor del desarrollo de Chile es el sector privado, sus opiniones deben ser siempre antecedentes importantes en la toma de decisiones de carácter político y cconómico; de lo contrario la decisión burocrática sin tales elementos de juicio puede llegar a constituir una falacia. Consecuentemente, la consulta permanente con aquél es indispensable para el actuar exterior de Chile.

Considerando la naturaleza lucrativa de la actividad privada, es evidente que su labor es intentar maximizar sus utilidades. Los intereses de aquéllos, por lo tanto, no siempre coincidirán con la percepción de la autoridad política respecto del "interés común"; đe allí el carácter consultivo de tal diálogo.

La experiencia chilena demuestra que parte del empresariado privado tiene generalmente una visión algo sesgada y parcelada del mundo. Ello, debido a que las extrapolaciones se hacen a nivel de sus contactos comerciales; los que por definición son limitados. Chile todavía no cuenta con empresas privadas verdaderamente transnacionales. De ello se infiere la necesidad de este sector por educarse y formarse èn lo que al ámbito internacional se refiere.

En el proceso de diálogo con el empresariado hay que cuidar de caer en la simplificación de que todas las entidades aglutinadoras del sector privado representan adecuadamente a sus mandantes. Como la práctica chilena de los últimos tiempos ha demostrado que ello no siempre es exacto, parece del todo pertinente crear una suerte de red de contactos que asegure una visión comprensiva y precisa de sus necesidades e intereses.
} 


\section{Políticas.}

Los países pequeños como Chile tienen escasa posibilidad de influir en los acontecimientos mundiales. Algunos instrumentos para hacer frente al nuevo mundo podrían ser:

a) Flexibilidad orgánica e institucional. El hecho de ser pequeños nos permitiría mayor elasticidad en nuestro accionar externo. Esta ductibilidad debería abarcar desde la movilidad del sector privado exportador para responder rápidamente a los cambios en los flujos y las demandas de los mercados internacionales, hasta un aparato público pequeño pero ágil y eficiente;

b) Adecuarse internamente. Ellosignifica modificar en el interior del país, las estructuras, las organizaciones, los métodos, o lo que corresponda; con el fin de minimizar los eventuales costos y cargas que el mundo extra fronterizo nos impondrá;

c) Agudizar el sentido de oportunidad. Requiere una acción externa coordinada en todos los frentes del quehacer internacional e, idealmente, adelantarse a los hechos. Es factible lograr cierta capacidad predictiva elaborando escenarios alternativos y respuestas predefinidas de frente a aquéllos. En este proceso son indispensables los "grupos creativos", totalmente libres para poder ser "irresponsables" frente a lo convencional, destinados a pensar, a crear, a desafiar la normalidad, a explorar la novedad, etc.; $y$,

d) Mentalidad rápida y flexible. Para aprovechar las ocasiones históricas que se vayan presentando; ${ }^{45}$

${ }^{45}$ Ejemplos de oportunidades. Cuando se creó el Banco Europeo de Reconstrucción y Fomento para países del Este (BERF), todo Estađo que lo desease pudo hacerse parte. México habría ingresado con un aporte nominal de US\$10.000. Hoy toda negociación financiera de los países de Europa del Este debe ser consultada con México. Chile supo, pudo, pero no se decidió. Hoy es tarde.

Se sabe que la Organización para la Cooperación y Desarrollo Económico (OCDE) se encuentra en proceso de cambio. Desde el 14 de marzo de 1990, Chile cumple los requisitos formales para intentar alguna forma de participación en ella. Hace aproximadamente dos años, México elaboró y llevó a cabo una estrategia para ser miembro de la OCDE. Ingresará junto a Corea en 1993 o 1994. Chile supo, pudo, pero no se decidió. Hoy es tarde.

ONU compra anualmente desde papel de oficina hasta aviones y sofisticados equipos computacionales por montos que varían entre US\$1.500 y US\$3.000 millones. Para vender a ONU se requiere estar incluido en ciertos catálogos especiales. Desde hace años, Argentina vende automóviles y otros productos a ONU. S6́lo desde 1992. Chile intenta aparecer en tales catálogos. Chile tiene buena imagen como modelo de desarrollo en los organismos internacionales. Siendo país en desarrollo tiene posiciones de país desarrollado en la mayoría de las materias económicas. Está "entre dos mundos" y, sin embargo, no ha maximizado el uso de tal situación especial debido, precisamente, a la falta de estrategia. 
e) Promocionarse como país. La dificultad que implica vender en el exterior productos chilenos (desde bienes hasta ideas) hace necesario un gran esfuerzo de promoción. Por la pequeñez de Chile en el contexto mundial esta labor ha de tener el carácter de permanente. La imagen es una de las claves del éxito a nivel institucional e internacional. Si bien ello requiere de recursos financieros, la imaginación tiene un ingrediente importante;

f) Polf́tica de prestigio. Basada en la realidad de ser un país serio, que cumple sus compromisos, ordenado, con instituciones funcionales públicas y privadas eficaces, sin corrupción, trabajadores disciplinados, sin excesiva burocracia, buen nivel educacional, etc. En fin, virtudes atractivas para el ambiente de los negocios;

g) Elaborar estrategias. No pudiendo Chile inducir a las potencias a actuar, siempre existe la posibilidad de formular estrategias que aumenten las probabilidades de obtener beneficios o minimizar. eventuales perjuicios;

h) Muitilateralismo. Para los países pequeños la mejor "póliza de seguros" es un sistema multilateral predecible, con normas claras, transparentes, objetivas, aplicables por igual a todos sus componentes e, idealmente, con un único sistema de solución de diferencias fuerte y autosuficiente;

i) Bilateralismo. No obstante la irrupción de otros actores en el concierto internacional, en el corto y mediano plazo, el Estado continuará en un rol primordial. Las relaciones bilaterales pueden ser potenciadas o debilitadas por peculiaridades como la comunidad de intereses frente a un tema específico, pertenencia a una asociación, un enemigo común; en fin, la relación coyuntural. También se ven afectadas por elementos de más largo plazo como principios, valores, historia, religión, región de influencia, vecindad, cultura u otros.

j) El sistema de bloques económicos. Este esquema lleva en su seno el germen de la exclusión arbitraria, tanto política como económico-comercial. Sólo puede ser considerado positivo en la medida de que tenga como condición "sine qua non" la profundización y reforzamiento del sistema multilateral. De intensificarse esta tendencia Chile deberá procurar quedar dentro y no fuera de aquéllos; y, ojalá "en los primeros carros del tren";

k) Grupos de interés. Esquemas de concertación distintos de los tradicionales, como los grupos de interés, han demostrado ser útiles 
si el compromiso por la empresa común es efectivo. El lazo de unión es la coyuntura de un mismo objetivo e independiente de la ideología política, el nivel de desarrollo u otro; ${ }^{46}$

i) Integración. Por lo inevitable de nuestra realidad geográfica, una prioridad exterior debiera ser la integración económica regional, para coadyuvar al logro de una América Latina democrática, estable y económicamente próspera. Todo ello, cuidando de no abortar nuestras propias posibilidades de desarrollo;

m) Cooperación internacional. En dos sentidos: aumentar aquélla orientada a la transferencia tecnológica en la pequeña y mediana empresa y al tema del medio ambiente; e, intensificar la cooperación técnica a nivel horizontal dentro de la región. Ya existen planes de asistencia en variadas áreas con países centroamericanos. Se debería incrementar tal contribución para mantener nuestra presencia en el área y reforzar los principios rectores de la nueva política exterior chilena (desarrollo, democracia y libre mercado);

n) Planteamiento público económico internacional. Chile deberá continuar con un discurso externo consistente con su quehacer interno. Vale decir, debería avanzar hacia una mayor apertura del comercio internacional: eliminando barreras arancelarias y para-arancelarias pero exigiendo reciprocidad; dando y solicitando acceso a los mercados; otorgando y promoviendo el trato nacional; evitando pero también reclamando la erradicación de prácticas desleales y prácticas comerciales restrictivas, etc.

\section{Conclusiones: un nuevo Ministerio de Relaciones Exteriores para Chile.}

En la actualidad, la Cancillería cumple razonablemente bien parte de las materias tratadas precedentemente, especialmente las de carácter político. ${ }^{47}$ Ello no obsta, sin embargo, a que pueda reformarse para

\footnotetext{
${ }^{46}$ Cairns, Grupo de Río, Países Antárticos, de la Cuenca del Pacífico (PECC y APEC), GIEC, entre otros.

${ }^{47}$ Las críticas son "fáciles": funciona mal, falta de iniciativa, demasiada lentitud, de escasa eficiencia, burocrático, prioriza inadecuadamente los temas exteriores del pais, etc. Si se solicita mayor precisión, los cuestionamientos tienden a concentrarse en la cuestión económica exterior y muy especialmente en las negociaciones económicas bilaterales; proceso en el que participan todos los Ministerios del sector económico.
} 
M. Matus B. / Hacia una nueva política exterior ...

aumentar su efectividad. Se requiere de una nueva estructura; tema que debería ser prioritario en un programa de modernización de la administración del Estado. Algunas de sus características serían:

a) Sistema de gestión. Debe ser moderno, ágil y flexible que le permita acomodarse a las nuevas situaciones. Ello requiere la unidad de las funciones políticas y económicas, tanto desde el punto de vista de las decisiones como de su ejecución; organizadas sobre la base de áreas geográficas. ${ }^{48}$

b) Estructura multilateral. Una unidad que concentre todos los organismos multilaterales mundiales, políticos y económicos. ${ }^{49}$ Los regionales deberían estar a cargo de las unidades regionales pertinentes, sean políticos o económicos; puesto que necesariamente tendrán un vínculo más estrecho con los Estados del área.

c) Grupos de trabajo ("task forces"). Debido a lo mutable del sistema internacional, es posible que la Cancillería no cuente con una estructura formal para hacer frente a todos los imprevistos de la nueva realidad. En tal sentido debería existir la política de crear grupos de trabajo, temporales y para tareas específicas.

d) Personal. ${ }^{50}$ A medida de que las materias exteriores aumentan en complejidad, las Cancillerías tenderán a incrementar su función coordinadora, organizadora y centralizadora de los diferentes puntos de vista técnicos. En igual proporción disminuirá su influencia en la formulación de políticas en materias fuera de su competencia, como ocurre hoy.

La diplomacia es una actividad que requiere capacidades particulares. En el futuro, la cualidad primordial del diplomático debería ser la capacidad para detectar, en el país de destino, las oportunidades para nuestro desarrollo, las sutilezas, potencialidad y métodos útiles para Chile. Lo mismo se trate de un organismo internacional, la secretaría de un bloque de países o un grupo de interés, etc. Consecuentemente y salvo en asuntos muy puntuales, las Cancillerías del siglo XXI requerirán profesionales con un alto nivel de conocimiento

\footnotetext{
${ }^{48} \mathrm{La}$ sección (de varias personas) sobre Estados Unidos, por ejemplo, llevaría las relaciones políticas y económicas y el seguimiento a lo negociado por los especialistas del área de negociaciones económicas internacionales, que se raenciona más adelante.

${ }^{49}$ Con exclusión del FMi, Banco Mundial y BID que, por su especialidad, deben continuar dependiendo del Ministerio de Hacienda.

${ }^{50} \mathrm{Ver}$ "The Foreign Service in 2001", Institute for the Study of Diplomacy, School of Foreign Service, Georgetown University, August 1992.
} 
en variadas materias como para poder hacer su seguimiento y llevar adelante eventuales negociaciones en armonía y complementación con especialistas que, en definitiva, impartirán las orientaciones técnicas pertinentes. Al mismo tiempo, sin embargo, deberán ser capaces de lograr una visión de conjunto, en un mundo cambiante e impredecible.

Lo anterior supone redefinir el sistema de admisión conforme a las nuevas necesidades, establecer métodos de promoción privilegiando la capacidad profesional, disponer de incentivos para tener un cuerpo profesional técnicamente competente, eficiente y eficaz. Ello implica disminuir la brecha entre las remuneraciones del sector privado y el Servicio Exterior, con el fin de aumentar la posibilidad de contar con buenos profesionales.

Igualmente, debe establecerse algún sistema que promueva y permita la salida fluida de tales funcionarios al sector privado, aumentando la dinámica interna de promociones.

e) Oficina de planificación o estudio. Elaborar escenarios posibles; escudriñar cualquier idea, proponer cursos de acción, sin otro límite que la finalidad última de la política exterior: el desarrollo del país. Esta actividad podría realizarse en dos niveles: una planificación macroestratégica de conflictos y tendencias; $y$, otra micro: orientada a problemas puntuales de zonas específicas, más cercanas a la región o escritorio correspondiente.

f) Promoción de la inversión. La inversión extranjera en Chile y la protección de la nacional en el exterior hacen necesaria una estructura especializada y diferente de la labor de promoción que realiza el Comité de Inversiones Extranjeras. Entonces, además de incorporarlo al quehacer de nueva Cancillería, ${ }^{51}$ es necesario avanzar hacia una etapa de mayor refinamiento o sofisticación: segmentar sectores específicos a los cuales se desea llegar y definir una política de protección de la inversión chilena en el exterior.

g) Sección de negociación económica. Esta debe estar organizada por sectores o temas específicos (ejemplo: reglas de origen, textiles, acceso, servicios, procedimientos de aduanas, propiedad intelectual, etc.). Su labor estaría centrada en el ámbito de las trata-

\footnotetext{
${ }^{51}$ Ello, en la medida de que el Comité continúe con la política actual: atraer inversión extranjera al país sin discriminación. Por el contrario, si se desea establecer alguna política distinta de aquélla, debería continuar dependiendo del Ministerio de Economía.
} 
M. Matus B. / Hacia una nueva política exterior

tivas económicas distintas de las ventas: acceso de productos chilenos en otros mercados, acuerdos de complementación económica, acuerdos de libre comercio, apoyo al establecimiento de empresas chilenas en el exterior, y negociaciones multilaterales económicas;

h) Contacto entre el sector público y el privado. La Cancillería debería establecer un permanente, fluido y estructurado contacto entre ambos, a fin de determinar sus necesidades, preocupaciones, prioridades, intereses, planes y proyecciones. De no apoyarse al empresariado nacional, aquél buscará tal ayuda en otros países. Es probable que, en el futuro, muchas empresas chilenas estén en condiciones de evaluar seriamente tal opción.

\section{OBRAS CITADAS O CONSULTADAS}

Akehurst, Michael,AModern Introduction to Intenatinal Law, (George Allen \& Unwin Ltd., 1984), $5^{\text {a }}$ edición.

Changing Our Ways: America and the New World/Carnagie Endowment Commission on America and the New World, 1992.

Calvocoressi, Peter, World Politics since 1945, (Nueva York: Longman Inc., 1982), $4^{8}$ edición.

Centro Latinoamericano de Economía y Política Internacional (CLEPI), Informe sobre la Economía Mundial - Perspectiva Latinoamericana 90-91.

CIEPLAN, Notas Técnicas.

Estudios Públicos, revista trimestral.

Feltham, R. G., Diplomatic Handbook, (London and New York: Longman, 1985), $4^{\mathrm{a}}$ edición.

Festugiere, La esencia de la Tragedia Griega, (España: Ariel, 1986).

Flaceliere, Robert, La vida cotidiana en Grecia en el siglo de Pericles, (Madrid: Temas de Hoy, 1989).

FLACSO, Cono Sur, revista bimensual.

FLACSO, De la reinserción a los Acuerdos. La política exterior chilena en 1991. Grenville, J. A. S., A World History of the Twentieth Century, (Glasgow: Fontana Press, 1986), vol. 1, Western Dominance 1900-45.

Institute for the Study of Diplomacy, "The Foreign Service in 2001", School of Foreign Service, Georgetown University, 1992.

Jaeger, Werner, Paideia: los ideales de la cuitura griega, (México: Fondo de Cultura Económica, 1957). 
Kamarck, Andrew, Economics and the Real World, (Oxford: Basil Blackwell, 1983).

Nietzsche, Friedrich, El origen de la Tragedia.

Report of the Senate Standing Committee on Foreign Affairs, Defence and Trade. Australia and Latin America, junio 1992.

Retamal, Julio, Y después de Occidente ¿qqué?, (Santiago: Editorial Conquista, 1986).

Rhoads, Steven, Visión Económica del Mundo: gobiemo, mercados y política pública, (México: Trillas, 1990).

The Washington Post, National Weekly Edition.

Tomassini, Luciano, La Política Intemacional en un Mundo Postmodemo, (Buenos Aires: Grupo Editor Latinoamericano, 1991).

Truyol y Serra, Antonio, La Sociedad Internacional, (Madrid: Alianza Editorial, 1987).

Tullock, Gordon, Private Wants, Publics Means: An Economic Analysis of the Desirable Scope of Government, (Nueva York: Basic Book, 1970).

UNDP, Human Development.

Wallace, Rebecca, International Law, (Great Britain: Sweet and Maxwell Limited, 1986).

Wells, H. G., Breve Historia del Mundo, (Buenos Aires: Ediciones Siglo Veinte, 1974). 